www.jmscr.igmpublication.org

Impact Factor 5.244

Index Copernicus Value: 83.27

ISSN (e)-2347-176x ISSN (p) 2455-0450

crossref DOI: _http://dx.doi.org/10.18535/jmscr/v4i10.33

Journal Of Medical Science And Clinical Research

\title{
Telemedicine- Reaching Out to the Unreached Rural Poor and As a Tool of CME
}

\author{
Authors \\ Dr Amol Kinge ${ }^{1}$, Dr Kamaxi Bhate ${ }^{2}$, Dr R. R. Shinde ${ }^{3}$, Dr Sumit Wasnik ${ }^{4}$ \\ ${ }^{1}$ MD Community Medicine \\ ${ }^{2}$ Professor, MD Community Medicine) Person for communication \\ ${ }^{3}$ Professor and Head of Department, MD Community Medicine \\ ${ }^{4} \mathrm{MD}$ Community Medicine \\ Seth GSMC and KEM hospital, Parel, Mumbai-12 \\ Corresponding Author \\ Dr Kamaxi Bhate \\ Email: bhatekamaxi@mail.com, mobile 9821033222
}

\begin{abstract}
Introduction- Telemedicine is used as an umbrella term that refers to the remote delivery of health-care information using electronic telecommunication and information technology. In other words, there is a transfer of medical and health information between distant sites/participants using telecommunication and information technology as a substitute for personal contact. Telemedicine technology can be utilized for a wide range of health-care needs. This fall into three major categories including: (a) Tele-consultation (b) tele-monitoring and support and (c) tele-education to provide academic exposure to the doctors serving in rural areas.

The aim of the study is to gain practical insights to evolve strategies for effective facilitation of Telemedicine with objectives are to assess the utilization patterns \& extent of utility of Telemedicine services in rural areas of Maharashtra and to map the morbidity patterns and epidemiological determinants of the patients reported to Telemedicine unit.

Materials \& Methods: Retrospective data analysis of all cases referred (Case documents / audio-video records) to telemedicine department of an Apex Institute KEM Hospital Mumbai from May 2008 to March 2014. Data was collected from telemedicine department in month of august 2014.

Results- 1) Referrals for diagnostic opinions predominate amongst the total cases reported through telemedicine. 2) Most cases were referred for "second opinion". However establishment of professional networking and main streaming of institutional competency is an added advantage. 3) Reaching out with CMEs to the doctors.

Conclusion- Telemedicine make specialty care more accessible and eliminating lengthy travel and costly transportation.

Keywords- telemedicine, ISRO, accessible rural health care.
\end{abstract}

\section{Introduction}

Telemedicine involves all the medical activity having an element of distance. In simple terminology, it can be defined as the use of communication networks for the exchange healthcare information to enable clinical care. Although, telemedicine has been practiced since hundred of years by means of letters, but with 
advancement of Information and Communication Technology, there has been a manifold increase in using telemedicine as a tool for delivering medical treatment. Telemedicine not only includes the real time consultation between patient and expert, but it also has the element of getting medical advises on prerecorded medical data such as in the case of 'teleradiology'or 'telepathology'. A more sophisticated model has been using it extensively for providing health care benefits to the unprivileged people.

Telemedicine is gaining ground in developing countries and even many clinicians in these countries have started practising telemedicine out of their professional needs. In a very simple form they are reaping the benefits of telemedicine by exchanging clinical information and comments through emails. Developing countries like India, Nepal and Bangladesh etc have opened up to telemedicine to address various issues being faced by their healthcare delivery system. On analyzing the role that telemedicine is playing in the developed and the developing world, it can be noted that, in the developed countries, telemedicine applications and utilities enact a virtual transportation in some sense. On the other hand, in the resource poor countries, telemedicine improves care and enhances access to healthcare (Sood S P BJS 2005). Thus telemedicine may have a more profound impact on the healthcare scenario in the developing countries than in the developed ones.

\section{BACKGROUND}

The Indian health care sector structured in three tiers viz., primary, secondary, and tertiary and it is characterized by the presence of several distinct systems of health care delivery such as the government, not-for-profit, charitable organizations, corporate hospitals, and smaller private clinics.

This health care system is grossly underfunded, under staffed, and poorly equipped. According to the approach paper for the $12^{\text {th }}$ five year plan, in $2010,10 \%$ of posts of doctors at the primary health centers, $63 \%$ of the specialist posts at the community health centers, $25 \%$ of the nursing posts at PHCs and CHCs combined, 27\% posts of pharmacist, and $50 \%$ of laboratory technician posts are vacant. (An approach to the 12th five year plan)

\section{Access to health care facilities in Urban and rural India:}

Urban population in India accounts for less than a third of its total population. Allopathic physicians are highly concentrated in urban areas compared to rural areas (13.3 and 3.3 per 10,000 populations, respectively). Nurses and midwives are also similarly concentrated in urban areas (15.9 and 4.1 per 10,000 populations).

(NFHS-3,.2005-06)

The density of allopathic physicians is 4.28 per 10,000 populations (NSSO 2005). There are approximately 0.81 nurses per allopathic physician in India, suggesting that there are more doctors than nurses. From a health systems point of view, the ratio of nurses to doctors is very low. According to the 1993 World Development Report, as a rule of thumb, the ratio of nurses to doctors should exceed 2:1 as a minimum with $4: 1$ or higher considered more satisfactory for costeffective and quality care. Nurses can deliver many of the basic clinical care and public health services, particularly at the community level, at a lower cost than trained physicians.

Out of the 660,856 doctors registered in India, only $12 \%$ are in the public sector. (NFHS-3 2005-

06)

The number of people not receiving treatment because of 'financial problem' and 'lack of medical facility' is higher in rural areas than in urban areas. (Dilip TR.2005). Although rural areas house $68 \%$ of the Indian population, only $20 \%$ of the total hospital beds are located in rural area (NFHS-3 2005-06)

An imbalance in the urban-rural distribution of specialists and perceived poor quality health care services in the rural areas result in almost two thirds of the patients in urban hospitals coming from rural areas.

Half of the rural population continues to live below the poverty line, struggling for better and 
easy access to health care and services (Dilip TR.2005).

In addition, poor Indian villagers spend most of their out-of-pocket health expenses on travel to the specialty hospitals in the city and for staying in the city along with their escorts. A recent study conducted by the Indian Institute of Public Opinion found that $89 \%$ of rural Indian patients have to travel about $8 \mathrm{~km}$ to access basic medical treatment, and the rest have to travel even further (Bagchi S.)

India's rural population is thus more vulnerable than its urban counterpart. Thus rural health care scene is characterized by: paucity of qualified doctors, almost non-availability of specialists and specialist care, several patients being serviced by unqualified practitioners, late discovery of ailment and delay in institution of appropriate treatment due also to greater time required for transport to urban/ district healthcare facilities and provision of healthcare by inexperienced primary healthcare service providers

\section{Indian Space Research Organization (ISRO) -} The efficacy of telemedicine has already been shown through the network established by the Indian Space Research Organization (ISRO), which has connected 22 super-specialty hospitals with 78 rural and remote hospitals across the country through its geo-stationary satellites. This network has enabled thousands of patients in remote places such as Jammu and Kashmir, Andaman and Nicobar Islands, the Lakshadweep Islands, and tribal areas of the central and northeastern regions of India to gain access to consultations with experts in super-specialty medical institution (ISRO Annual Report 20042005).

There are other indications that the telemedicine initiative may have had a positive impact. ISRO's annual report for 2004-2005 states: "More than 25,000 patients have so far been provided with teleconsultation and treatment. An impact study conducted on a thousand patients has revealed that there is a significant cost saving in the system since the patients avoid expenses towards travel, stay, and for treatment at the hospitals in the cities" (ISRO Annual Report 2004-2005). Dr. Devi Shetty, a cardiac surgeon and the Chairman of Narayan Hrudayalya, a hospital that has served thousands through telemedicine, said: "We have treated 17,400 patients using telemedicine connectivity in various parts of India, mainly from rural India, and [a] few patients from outside India. We use both satellite as well as ISDN connectivity. Now, with the Indian Space Research Organisation, which is our associate in this project giving us the satellite connection free of cost, we have a [larger] game plan of offering health care to African and other Asian countries."

\section{AIM AND OBJECTIVES OF STUDY}

Aim: To gain practical insights to evolve strategies for effective facilitation of Telemedicine Objectives:

- To assess the utilization patterns \& extent of utility of Telemedicine services in rural areas of Maharashtra

- To map the morbidity patterns and epidemiological determinants of the patients reported to Telemedicine unit.

\section{Materials \& Methods}

1. Retrospective data analysis of cases referred to telemedicine department of an Apex Institute KEM Hospital Mumbai from May 2008 to March 2014.

2. Study Unit: Cases referred (Case documents/audio-video records) to telemedicine department of an apex institute.

3. Sampling Method: All the cases referred to telemedicine department were included in the study.

4. Study Period: Data was collected from telemedicine department in month of august 2014.

5. Data was entered using Microsoft-Excel 2007 Software.

\section{Telemedicine in Maharashtra}

The Maharashtra State Telemedicine project is a part of initiative undertaken by Government of 
India and World Health Organisation. Telemedicine is one of the key initiatives under National

Rural Health Mission (NRHM) to improve the health services for the rural people of India.

The Government of Maharashtra launched its pilot project on Telemedicine in the year 2007, with one Specialist node at KEM Hospital, Parel, Mumbai and 5 sub district hospitals. The prime target areas for this intervention were tribal areas such as those of Sindhudurg, Nandurbar, Beed and Satara. The second phase of expansion involved participation of 5 specialist node, 23 district hospitals and 4 sub-district hospitals.

There are two end in telemedicine viz. Specialist End and Patient End. The Specialist end consists of Five Medical colleges. The medical Colleges that have been developed as specialist end are
KEM Hospital Mumbai, B. J. Medical College Pune, GMC Aurangabad, GMC Nagpur, and Sir J. J. Hospital Mumbai. Nanavati Hospital at Mumbai has been made has honorary specialist centre. The J. J. Hospital at Mumbai has a dual role to play. It acts as main server centre for coordinating between the specialist centers and patient centers (Kumar R, Choudhary P, Pasha S). Additionally, it also provides consultation service for the referred patient through teleconference. The patient end constitutes of 27 districts hospitals of Maharashtra. Furthermore 4 Sub district hospitals in each district acts as centers where patient from nearby areas come for consulting the doctors. All the district and sub district hospitals are equipped with modern state of art telecommunication network system for carrying out teleconferences.

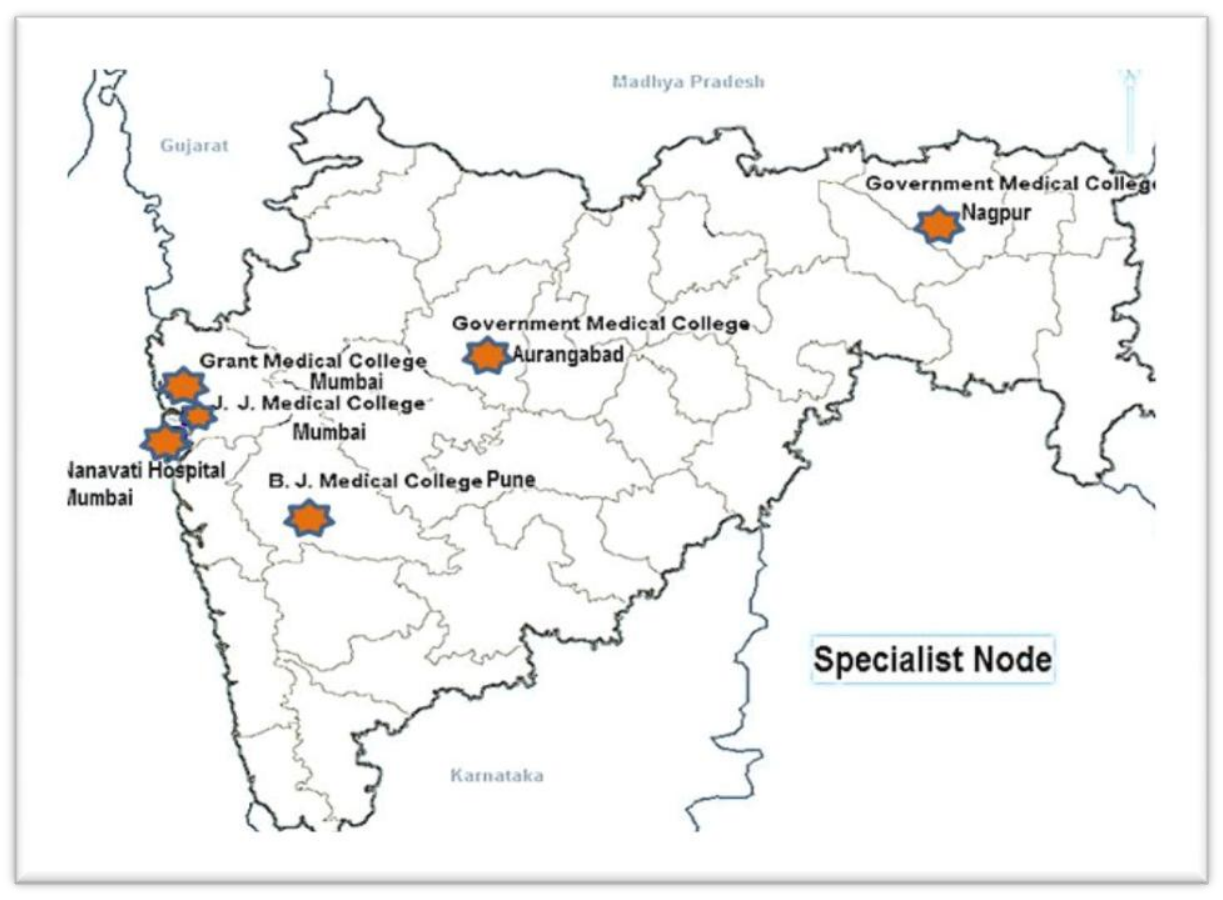

\section{Telemedicine in KEM Hospital:}

KEM Telemedicine Centre offers consultation in all specialties and super-specialties includingMedicine, Surgery, Obstetrics and Gynecology, Pediatrics, Pediatric Surgery, Cardiology, Cardiosurgery, Neurology, Chest Medicine, Ophthalmology, Skin and VD, ENT, Orthopedics, Radiology, Hematology, Nephrology, Gastrointestinal Surgery, Neonatology, Ayurveda,
Anesthesia, Endocrinology, Urology, Dentistry, Psychiatry, etc

\section{Process of Consultation}

1. Cases are referred from the referring district / rural hospitals to telemedicine department of KEM Hospital using special software.

2. Specialty opinion is offered by senior consultants from KEM Telemedicine 
Centre by reviewing the history/ case notes and investigations/ reports available. Additional clinical data and investigations are requested if necessary.

3. Patient can be physically seen and spoken with (if required) using the web-camera and viewing set

4. Appropriate follow up, referral and supportive care offered to patients from district/ rural hospitals

\section{RESULTS}

Figure No 1-Number of Cases Seen in KEM Telemedicine Centre

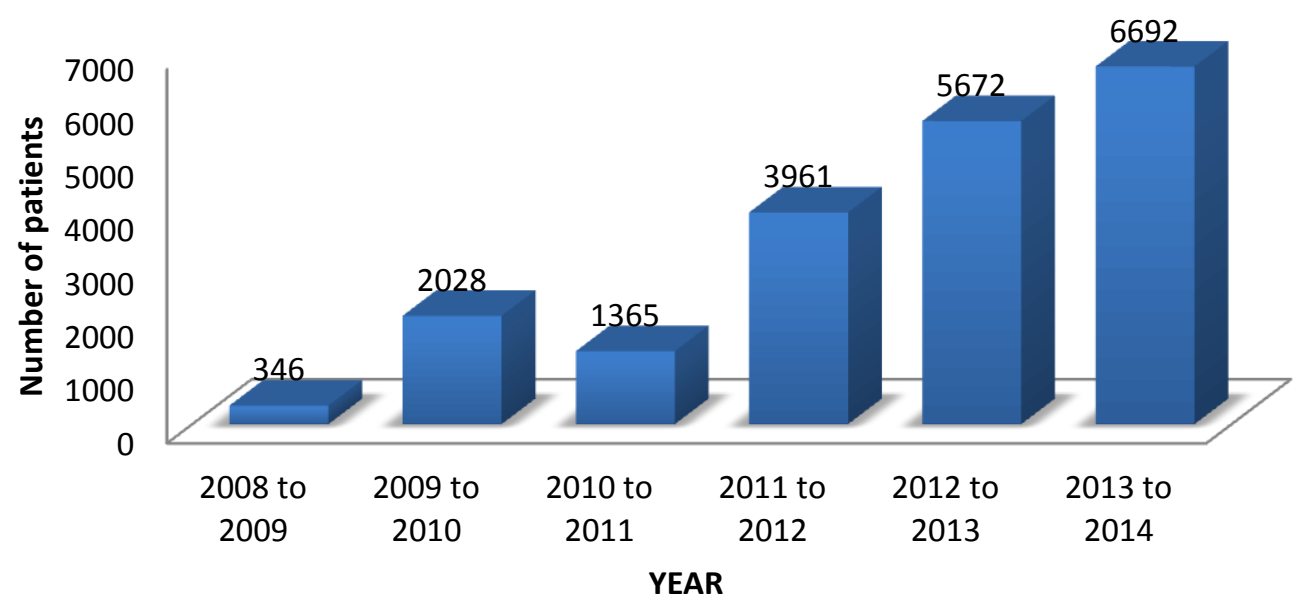

Figure No 2- Number of Cases Seen Department Wise

\begin{tabular}{|l|c|c|c|c|c|c|}
\hline Department & $\begin{array}{c}\text { May 08 - } \\
\text { March 09 }\end{array}$ & $\begin{array}{c}\text { April 09 - } \\
\text { March 10 }\end{array}$ & $\begin{array}{c}\text { April 10 - } \\
\text { March 11 }\end{array}$ & $\begin{array}{c}\text { April 11- } \\
\text { March 12 }\end{array}$ & $\begin{array}{c}\text { April 12 - } \\
\text { March 13 }\end{array}$ & $\begin{array}{c}\text { April 13- } \\
\text { March 14 }\end{array}$ \\
\hline Medicine & 100 & 131 & 94 & 865 & 818 & 711 \\
\hline Surgery & 14 & 51 & 8 & 88 & 90 & 118 \\
\hline OBGY & 8 & 24 & 5 & 84 & 51 & 81 \\
\hline Pediatrics & 32 & 52 & 56 & 350 & 335 & 226 \\
\hline Cardiology & 27 & 24 & 10 & 75 & 62 & 117 \\
\hline Neurology & 30 & 13 & 8 & 53 & 82 & 74 \\
\hline ENT \& Ophth & 21 & 33 & 22 & 94 & 108 & 213 \\
\hline Skin VD & 16 & 34 & 21 & 242 & 400 & 516 \\
\hline Orthopedics & 24 & 136 & 151 & 219 & 326 & 290 \\
\hline Radiology & 42 & 1472 & 955 & 1248 & 2754 & 3118 \\
\hline Others & 32 & 58 & 35 & 643 & 646 & 1263 \\
\hline Total & 346 & 2028 & 1365 & 3961 & 5672 & 6727 \\
\hline
\end{tabular}


Figure No 3- Number of Other Cases Seen Department Wise

\begin{tabular}{|l|l|l|l|l|l|l|}
\hline Other Department & $\begin{array}{l}\text { May 08 } \\
\text { March09 }\end{array}$ & $\begin{array}{l}\text { April 09 } \\
\text { March10 }\end{array}$ & $\begin{array}{l}\text { April } \\
\text { March 11 }\end{array}$ & $\begin{array}{l}\text { April 11 } \\
\text { March12 }\end{array}$ & $\begin{array}{l}\text { April 12 } \\
\text { March13 }\end{array}$ & $\begin{array}{l}\text { April13 } \\
\text { March14 }\end{array}$ \\
\hline Anesthesia & 0 & 10 & 1 & 3 & 2 & 1 \\
\hline Psychiatry & 0 & 4 & 1 & 55 & 20 & 12 \\
\hline ART & 0 & - & - & -- & & 0 \\
\hline CVTS & 0 & & 1 & 11 & 27 & 18 \\
\hline Forensic & 0 & & & 4 & & 0 \\
\hline Neuro Surgery & 4 & 4 & 5 & 20 & 22 & 21 \\
\hline Physiotherapy & 0 & & & 3 & & 0 \\
\hline Unani & 0 & & & - & & 0 \\
\hline Urology & 1 & 3 & 2 & 3 & 14 & 13 \\
\hline Pathology & 0 & & & - & 6 & 0 \\
\hline GI Surgery & 4 & 5 & 8 & - & 14 & 2 \\
\hline GI Medicine & 2 & & 2 & 12 & 11 & 14 \\
\hline Dentistry & 2 & 2 & 2 & 61 & 85 & 120 \\
\hline Nephrology & 7 & 2 & 2 & 5 & 7 & 26 \\
\hline Endocrinology & 2 & 3 & 2 & 86 & 64 & 56 \\
\hline Neonatology & 0 & 3 & 3 & 13 & 16 & 17 \\
\hline Hematology & 7 & 15 & & - & 270 & 291 \\
\hline Ayurvedic & 3 & 7 & 6 & 367 & 88 & 672 \\
\hline Total & 32 & 58 & 35 & 643 & 646 & 1263 \\
\hline
\end{tabular}

\section{b. CME and Telemedicine}

Workshops are regularly held on different topics with the help of telemedicine in KEM hospital. Some examples are as follows- Clinical Case discussion:

1) Microbiology - Rational antibiotic therapy

2) Psychiatry - Biological Factors affecting medical disorders

3) Skin \& VD -Skin Disease

4) GI Medicine -Interpretation of abnormal LFT

5) Occupational therapy -International exchange programme

6) Transfusion medicine

\section{Discussion}

It is observed that there is a increasing trend in the number of patients referred to the telemedicine department of KEM hospital since its establishment in the year of 2008 except in the period of April 2010 to March 2011, where it was seen that because of some technical problems like internet and maintenance issues there was a slight decrease in the total number of patients.

Use of telemedicine is increasing every year in this telemedicine center. Radiology is the department where most of the cases (records) were referred for higher opinion via telemedicine. Patient records are also referred to other department like hematology, dental, ayurvedic, anesthesia, psychiatry etc.

The practice of telemedicine - through transmission of digitized data, audio, video and images - is getting popular all over the world as it provides hitherto unavailable access to tertiary level specialist healthcare even in geographically remotest areas without displacement of the patient, physician or the equipment.

It is not only cost-effective to the patient but costbeneficial to the society also. More and more doctors and patients are resorting to the use of telemedicine due to its advantages of convenience 
and cost-saving. The practice of telemedicine, however, has brought with it several complicated issues. These issues involve not only healthcare workers and consumers but the society, technologists and the lawmakers also. Those interested in the specialty of telemedicine need to address these issues.

Advantages of Telemedicine: The main objetctive of telemedicine is to cross the geographical barries and provide healthcare facilities to rural and remote areas (health for all) so it is beneficial for the population living in isolated communities. Besides this other advantages telemedicine are

1) It improves access to quality health care services and eliminate distance barriers, reduces the time and cost of travelling for the patients and improve access to quality health services

2) In emergency and critical care situations where moving a patient may be undesirable and / or not feasible.

3) Facilitate patients and rural practitioners' access to specialist health services and support

4) Reduce unnecessary travel time for health professionals

5) Reduce isolation of rural practice by upgrading their knowledge through teleeducation or tele CME.

\section{Barriers in Telemedicine:}

1) Doctors - patient's relationship: The survey conducted by SGPGIMS telefollow up program for the patients of Orissa state revealed that $99 \%$ patients were satisfied with using telemedicine technology as this service reduced their travelling time and cost. In teleconsultation they were also happy that they get the specialist consultation and their cases have been seen by some expert doctors.

However, some resistance is seen amongst doctors. Doctors in government sector tend to look upon telemedicine as an additional duty or workload. Therefore, there is need to weave telemedicine into the routine duties of the doctors.

2) Availability of Technology at a Reasonable Cost: It is myth that to establish a telemedicine platform is an expensive. The basic system needs hardware, software and telecommunication link. In all the areas there is a significant reduction in the prices. Most of these costs are well within the reach of most of the hospitals, and can be recovered by nominal charge to the patients and students in case of tele-education which would be much less than the physically traveling.

3) Reliability: Some healthcare professionals have doubt about the quality of images transmitted for teleconsultation and telediagnois. In tele-radiology, telepathology, tele-dermatology the quality of image (colour, resolution, field of view, etc) should be international standards to avoid any wrong interpretation and misdiagnosis.

4) Funding/ Reimbursement Issues: There should be a format to calculate the investment and recurring cost of the telemedicine system. The insurance companies have to decide whether the cost of tele-healthcare should be reimburse or not.

5) Lack of Trained Manpower: There is lack of training facilities with regards to application of IT in the field of medicine. Most of the healthcare and IT professionals are not familiar with the terms commonly used in telemedicine such as HIS, EMR, PACS, etc. Telemedicine is also not the part of course curriculum of medical schools.

6) Privacy and Security Concerns: There are many issue that should be considered regarding the security, privacy and confidentiality of patient data, in telemedicine consultations How are 
patients' rights of confidentiality of their personal data ensured and protected How to ensure security of the data and restrict its availability to only those for whom it is intended and who are authorised and entitled to view it?

India's telemedicine initiative has the potential to provide specialized health care to millions of poor Indians. This potential was well summed up by Dr. Devi Shetty: "In terms of disease management, there is $99 \%$ possibility that the person who is unwell does not require operation. If you don't operate you don't need to touch the patient. And if you don't need to touch the patient, you don't need to be there. You can be anywhere, since the decision on healthcare management is based on history and interpretation of images and chemistry ... so technically speaking, $99 \%$ of health-care problems can be managed by the doctors staying at a remote place-linked by telemedicine."

\section{Bibliography}

1. Sood S P BJS. Development of telemedicine technology in India: Sanjeevani- An integrated telemedicine application. J Poster Med. 2005;51(4):30811

2. Government of India- Faster, sustainable and more inclusive growth: An approach to the 12th five year plan. New Delhi, 2011. Available from: http://planningcommission.nic.in/plans/pla nrel/12appdrft/appraoch_12plan.pdf)

3. International Institute for Population Sciences and Macro International (September 2007). "National Family Health Survey (NFHS-3), 2005-06". Ministry of Health and Family Welfare, Government of India. p. 436-40. Available from:

http://www.measuredhs.com/pubs/pdf/FRI

ND3/FRIND3-Vol1AndVol2.pdf [Last accessed on 2012 Oct 05)
4. National Sample Survey Organisation [NSSO]. National Sample Survey, $61{ }^{\text {st }}$ Round. New Delhi: Ministry of Statistics and Programme Implementation, Government of India; 2005

5. Dilip TR.2005 Extent of Inequity in Access to Health Care Services in India, In: Gangolli L, Duggal R, Shukla A, editors. Review of Health Care in India, CEHAT, Mumbai, 2005).

6. ref- International Institute for Population Sciences and Macro International (September 2007). "National Family Health Survey (NFHS-3), 2005-06". Ministry of Health and Family Welfare, Government of India. p. 436-40. Available from:

http://www.measuredhs.com/pubs/pdf/FRI ND3/FRIND3- Vol1AndVol2.pdf [Last accessed on 2012 Oct 05])

7. Dilip TR. Extent of Inequity in Access to Health Care Services in India, In: Gangolli L, Duggal R, Shukla A, editors. Review of Health Care in India, CEHAT, Mumbai, 2005)

8. Bagchi $\mathrm{S}$. telemedicine in rural India. (http://www.pubmedcentral.nih.gov/article render.fcgi?artid=1420376\&tool=pmcentr ez\&rendertype $=$ abstract)

9. [Indian Space Research Organisation (2005) (ISRO Annual Report 2004-2005): Space Applications. Available: http://www.isro.org/rep2005/Sp aceApplications.htm. Accessed 27 January 2006]

10. Kumar R, Choudhary P, Pasha S. Telemedicine in the State of Maharashtra: a case study. 2012 [cited 2014 Sep 29];(May):24-6 Available from: http://csidl.org/handle/123456789/219 